\title{
Cuadro básico, principios y criterios para protección y asistencia aplicable a los proyectos de repatriación voluntaria de los refugiados salvadoreños
}

\author{
Denis Racicott*
}

\section{INTRODUCCION}

La obra del Padre Segundo Montes, S.J., cuenta quizás con los estudios más desarrollados en la región latinoamericana sobre los temas de los refugiados, de los desplazados y de los repatriados. En EI Salvador es ya conocida la amplitud del fenómeno del desplazamiento tanto interno como externo. Cientos de miles de personas huyeron de sus casas, de sus tierras, de sus pueblos, a raíz del desarrollo de vastas operaciones militares de tipo contrainsurgente que provocaban grandes masacres y daños a la población civil en el campo, ya sea por el uso indiscriminado del su poder de fuego por parte de la Fuerza Armada o simplemente huyeron en la medida de la evolución del conflicto bélico.

Con el presente trabajo queremos presentar un cuadro básico de derechos, principios y criterios para protección y asistencia aplicable a la repatriación voluntaria de refugiados. En particular ese cuadro tiene por objetivo clarificar la situación jurídica de los proyectos de repatriación de los refugiados salvadorenos. Por este motivo, el cuadro se concentra en

- Abogado, subdirector IDHUCA. Parte del trabajo fue elaborado en 1987, a tftulo de investigador visitante en el IDHUCA, como becario de la Agencia Canadiense para el Desarrollo Internacional (A.C.D.I.) 
los aspectos más problemáticos de esos proyectos de repatriación, y no se intenta en este dar respuesta a todas las interrogantes sobre la materia.

El cuadro se basa en normas del derecho internacional público, asl como en normas del derecho internacional de los derechos humanos y normas relacionadas a la protección internacional de los refugiados. También, se apoya en normas del derecho constitucional de El Salvador.

El Alto Comisionado de las Naciones Unidas para los Refugiados (ACNUR) es el organismo encargado por la comunidad internacional de velar en cualquier parte del mundo por la protección de los refugiados. Igualmente, es obligado a buscar soluciones permanentes al problema de los refugiados. Históricamente, estas dos tareas fueron la esencia de su trabajo, derivadas de su mandato y Estatuto propio, como a continuación se detalla.

"1. El Alto Comisionado de las Naciones Unidas para los Refugiados, actuando bajo la autoridad de la Asamblea General, asumirá la función de proporcionar protección internacional, bajo los auspicios de las Naciones Unidas, a los refugiados que reunan las condiciones previstas en el presente Estatuto, y de buscar soluciones permanentes al problema de los refugiados, ayudando a los Gobiernos y, con sujeción a la aprobación de los Gobiernos interesados, a las organizaciones privadas, a facilitar la repatriación voluntaria de tales refugiados o su asimilación en nuevas comunidades nacionales".'

Como lo constatamos, en la búsqueda de soluciones al problema de los refugiados, el ACNUR está obligado por su Estatuto a implementar en forma particular la repatriación voluntaria.

La comunidad internacional tiene una larga experiencia en el presente siglo de fenómenos de éxodo masivo de población, y por consiguiente de búsqueda de soluciones permanentes al problema de los refugiados.

De esa experiencia, la repatriación voluntaria, por seguir el objetivo final de reintegrar socialmente el refugiado en su propio medio, es considerada por todos como la solución más adecuada al problema del refugio. La Asamblea General de las Naciones Unidas se pronunció en muchas ocasiones en su favor ${ }^{2}$. El Comité Ejecutivo del Programa del ACNUR le ha dedicado dos conclusiones fundamentales hasta la fecha la primera aprobada en el 310. periodo de sesiones del Comité Ejecutivo, en 1980 (No. 18 (XXXI)) y una segunda en el 360. periodo de sesiones, en 1985, (No.4, (XXXVI)) las cuales recogen los criterios y la práctica internacional sobre la materia. También múltiples organismos, coloquios 
o instancias de nivel internacional, subregional y regional como nacional reiteraron en los últimos anos su apoyo a la repatriación voluntaria como mecanismo de alivio idóneo a la tragedia del exilio.

Entonces, como veremos a continuación, la repatriación voluntaria de los refugiados a su pals de origen y a sus propias comunidades es hoy en dla una regla universal y la solución más favorecida al espinoso problema del refugio. Solo la repatriación voluntaria, por el hecho de permitir el retorno a su patria, a su tierra o a su casa propia asegura los refugiados del ejercicio pleno de sus derechos humanos de regresar libremente a su lugar de origen y de volver a gozar del beneficio de la protección de su pais.

\section{DERECHO DE REPATRIACION}

A pesar que no existe un texto especifico, el derecho de repatriación, ampliamente reconocido hoy en dia, se fundamenta en normas del derecho intemacional público, del derecho internacional de los derechos humanos como en normas de la legislación nacional salvadorena que garantizan a cualquier ser humano el derecho de REGRESAR LIBREMENTE A SU PAIS DE ORIGEN $y$ a SU PROPIA COMUNIDAD.

Asi la Declaración Universal de Derechos Humanos, en su articulo $13^{3}$ consagra el derecho a salir de cualquier pais, y a regresar a su pais. EI Pacto Internacional de Derechos Civiles y Políticos en su artículo $12^{4}$ especifica que nadie podrá ser arbitrariamente privado del derecho a entrar a su propio pais. Al nivel regional, la Convención Americana sobre Derechos Humanos (llamada también "Pacto de San José, Costa Rica") sefala en su artículo $22^{5}$ que nadie puede ser privado del derecho a ingresar en el territorio del Estado del cual es nacional.

Parece importante destacar que los derechos fijados tanto por el Pacto Internacional de Derechos Civiles y Políticos como por la Convención Americana sobre Derechos Humanos, tienen obligatoriedad en EI Salvador en virtud de la Constitución de la República (Artículos 1 y 144), los cuales después de haber sido suscritos, fueron ratificados por el Estado de El Salvador el día 23 de Noviembre de 1979 y el día 15 de Junio de 1978 respectivamente. Eso tiene por consecuencia que la ley no podria modificar o derogar lo acordado en esos tratados vigentes para El Salvador y en caso de conflicto entre los tratados y la ley, prevalecerán esos tratados.

Además las normas mencionadas precedentemente, en particular los derechos enunciados por la Declaración Universal de Derechos Humanos como normas básicas y fundamentales de los Derechos Humanos 
son hoy en dia tan generalizadas y tan universales que se considera que forman parte de las normas imperativas y principios generales del derecho internacional público (o sea parte de to denominado JUS COGENS). Por ese caracter intrinseco y valor superior, el respeto de esas normas de derechos humanos constituye por los Estados una obligación ERGA OMNES. Por obligación ERGA OMNES es entendido que todos los Estados, como miembros de la comunidad de los Estados tienen interés en asegurar que esas normas sean respetadas y protegidas. Estas normas que fijan los comportamientos que deben adoptar los Estados son consideradas como normas sagradas del derecho internacional público, atributos del ser humano por su condición de persona, con un valor superior al poder del Estado, constituyendo asl una limltación a su ejercicio. En este sentido, el derecho de regresar libremente a su pais de origen podría ser considerado como una norma imperativa del derecho internacional público.

Por último, hay que senalar que la propia Constitución de la República de El Salvador consagra ese derecho fundamental de regreso libre a su pals cuando enuncia en su artículo 5 que no se podrla prohibir la entrada en el territorio de la república a ningún salvadoreño.

Es importante notar que las normas citadas no preveen ningún acondicionamiento previo de cualquier índole a su ejercicio. Más bien se trata de un derecho preciso y categórico.

\section{RETORNO AL LUGAR DE ORIGEN O DE RESIDENCIA ANTE- RIOR DE LOS REPATRIADOS}

Además del derecho de regresar libremente a su pais, también son hoy universales y generalizados esos otros derechos básicos y fundamentales de elegir libremente su lugar de residencia en su propio pais, y de circular libremente en aquello.

Asi la Declaración Universal de Derechos Humanos prevee en su Articulo 13.1 que toda persona tiene derecho a circular libremente y a elegir su residencia en el territorio de un Estado. El Pacto Internacional de Derechos Civiles y Políticos prevee al respecto que toda persona que se halle legalmente en el territorio de un Estado tendrá derecho a circular libremente por el y a escoger libremente en el su residencia (Artículo 12.1). Asi lo afirma también la Declaración Americana de los Derechos y Deberes del Hombre, en su artículo VIII cuando expone que toda persona tiene el derecho de fijar su residencia en el territorio del Estado de que se nacionaliza, de transitar por el libremente y no abandonarlo sino por su voluntad. Por último la Convención Americana sobre Derechos Humanos establece en su artículo 22.1 que toda persona que se 
halle legalmente en el territorio de un Estado tiene derecho a circular por el mismo y a residir en el con sujeción a las disposiciones legales.

Vale notar de nuevo que estos derechos son considerados como normas imperativas del Derecho Internacional Público, cuya obsenvancia compete a la comunidad de los Estados en razón de su caracter y de su Importancia.

En el mismo sentido, la Constitución de la República de El Salvador prevee respecto a esos derechos en su Artículo 5 que toda persona tiene libertad de entrar, de permanecer en el territorio de la República y salir de éste, salvo las limitaciones que la Ley establezca. Además el mismo Articulo enuncia que nadie puede ser obligado a cambiar de domicilio o residencia, sino por mandato de autoridad judicial, en los casos especiales y mediante los requisitos que la ley senala. En este sentido la ley fundamental ratifica estos derechos básicos.

Igualmente estos derechos fueron reafirmados en distintas ocasiones en el escenario intemacional. Por ejemplo, el Coloquio sobre la Protección Internacional de los Refugiados en América Central, México y Panamá: Problemas Jurídicos y Humanitarios que adoptó la "DECLARACION DE CARTAGENA" concluyó al respecto:

"DUODECIMA. Reiterar el caracter voluntario e individual de la repatriación de los refugiados y la necesidad de que esta se produzca...preferentemente al lugar de residencia del refugiado en su país de origen.".s.

Por su parte el Grupo de Expertos encargado de elaborar el documento de "Principios y Criterios para la Protección y Asistencia a los Refugiados, Repatriados y Desplazados Centroamericanos en América Latina" a la ocasión de la Conferencia Internacional sobre Refugiados Centroamericanos (CIREFCA) opinó al respecto:

“59. Esta repatriación... de preferencia, si asi lo desean los refugiados, debe efectuarse al lugar de origen o de anterior residencia. Este elemento básico de la protección del refugio se deriva ... del derecho a la libertad de movimiento y libre elección del lugar de residencia. En el contexto regional en donde una gran mayoría de refugiados son de origen nural, es particularmente importante que puedan retornar a sus actividades". ${ }^{4}$

Sobre estos antecedentes, CIREFCA reiteró el compromiso de los Estados implicados en su Plan de Acción Concertado, de "continuar respetando la facultad de los refugiados de escoger el lugar de destino en su país, así como su libertad de movimiento y la libre elección del lugar de residencia en iguales condiciones a sus connacionales". ${ }^{5}$ 


\section{REPATRIARSE CON GARANTIAS, BAJO CONDICIONES DE SEGURIDAD Y DIGNIDAD Y SIN DISCRIMINACION}

Por razón de su mandato de protección a los refugiados, y por su propia experiencia como órgano especializado de las Naciones Unidas, el ACNUR debe insistir en el hecho que cualquier repatriación voluntaria de tipo colectivo que tenga lugar debia respetar el principio fundamental de la existencia en el pais de origen de condiciones de seguridad personal y dignidad, y un contexto de garantlas, además de ser hecha sin discriminación. Eso es particularmente vital cuando el ACNUR se enfrenta a una repatriación de larga escala, o masiva y el retorno de toda una comunidad de refugiados en medio de un conflicto bélico no resuelto como es el caso en El Salvador.

Asl lo determinó el Comité Ejecutivo del Programa del ACNUR cuando adoptó sus dos Conclusiones sobre la Repatriación Voluntaria:

7) Pidió a los Gobiernos de los paises de origen que diesen garantlas formales de la seguridad de los refugiados que regresasen, y destacar la importancia de que esas garantlas se respetaran plenamente y de que no impusieran sanciones a los refugiados que regresaban por el hecho de haber abandonado su país de origen por razones que hablan dado lugar a la situación de refugiados" e $^{\text {. }}$

En 1985, el Comité Ejecutivo del Programa del ACNUR agregó que era responsabilidad de los Estados procurar seguridad a sus súbditos, y tener voluntad política de crear las condiciones que faciliten esa solución.

"d) La Comunidad Internacional debia reafirmar que incumbla a los Estados hacerse responsables de sus connacionales y que otros Estados tenian el deber de promover la repatriación voluntaria. De modo análogo la promoción de la repatriación voluntaria como solución a los problemas de los refugiados requiera que los Estados directamente interesados tuvieran voluntad política de crear las condiciones que facilitasen esa solución. Esa es la responsabilidad principal de los Estados $^{\text {"7. }}$.

La DECLARACION DE CARTAGENA tenia sobre ese tema fundamental la conclusión siguiente:

"DUODECIMA. Reiterar el caracter voluntario e individual de la repatriación de los refugiados y la necesidad de que esta se produzca en condiciones de completa seguridad... ${ }^{8}$

El Grupo de Expertos por CIREFCA concluyó en el mismo sentido sobre estos importantes criterios: 
"56. ... los repatriados tienen el derecho de ser protegidos de tal manera que puedan efectivamente ejercer el derecho de volver a su pais voluntariamente.

59. ... esta repatriación debe tener lugar bajo condiciones de seguridad y dignidad... Este elemento básico de la protección del refugiado se deriva de los derechos humanos fundamentales de seguridad y liber$\operatorname{tad} . . .{ }^{\prime \prime}$

Es en base de todos estos antecedentes que CIREFCA pudo reafirmar sin vacilación el compromiso de los paises representados de "favorecer el retorno voluntario de los refugiados y otras personas desplazadas por la crisis, en condiciones de seguridad y dignidad personal que permita reanudar una vida normal" 10. También los Estados afectados participantes reiteraron su adhesión a los principios fundamentales de derechos humanos y protección de los refugiados", asi como el compromiso de respetar la necesidad que la repatriación tiene lugar bajo condiciones de seguridad y dignidad'2. Vale subrayar que el Estado salvadorefo participó a dicha Conferencia y es Parte en todos los compromisos adheridos en esta ocasión.

Ahora bien, qué significa la expresión "con garantlas, bajo condiciones de seguridad y dignidad y sin descriminación"

Es innegable que un contexto de garantías según ese criterio se basa en el estricto respeto del conjunto de los derechos humanos fundamentales como el derecho a la vida, a la integridad personal, a la seguridad, a la libertad de las personas, al reconocimiento a la personalidad jurldica, al principio de igualdad ante la ley, a la nacionalidad, a las garantlas judiciales para la protección de tales derechos previstos por los distintos instrumentos internacionales sobre derechos humanos ratificados por El Salvador. También incluye la protección acordada por los Convenios de Ginebra de 1949 relativos al derecho internacional humanitario y la protección a las victimas de los conflictos no-internacional prevista y el Protocolo II adicional a dichos convenios, igualmente suscrito y ratificado por El Salvador. Es innegable que esos derechos tan básicos y tan fundamentales para la persona humana son aplicables en todo momento a los repatriados como a los demás ciudadanos, y no pueden sufrir ningún acondicionamiento, suspensión, limitación o restricción. Además, es obvio que todos los demas derechos humanos (civiles y políticios, económicos sociales y culturales) garantizados por los mismos instrumentos jurídicos tienen su pleno efecto por los repatriados como a sus connacionales. 


\section{EL INTERES DE LA COMUNIDAD INTERNACIONAL EN LOS PROVECTOS DE REPATRIACION VOLUNTARIA}

Es reconocido hoy en dia el INTERES FUNDAMENTAL que tiene toda la comunidad internacional, a través del ACNUR, y de las Naciones Unidas en general en el debido cumplimento y al fiel respeto de sus obligaciones internacionales y ofertas de garantías por parte del Estado de origen al momento de realizar un programa de repatriación.

Asl la estableció el Comité Ejecutivo del Programa del ACNUR:

h) CONSIDERO que podía pedirse a la Oficina con el acuerdo de las partes interesadas, que observase la situación de los refugiados que regresaran con referencia especial a cualesquiera garantlas ofrecidas por los Gobiernos de los paises de origen; ${ }^{13}$

En la ocasión de la adopción de su Conclusión en 1985, el Comité Ejecutivo del ACNUR vino a reforzar su anterior conclusión aclarando el rol que compete al ACNUR:

"I) Se debia reconocer que el Alto Comisionado posela un interés legítimo respecto de las consecuencias del regreso, sobre todo cuando dicho regreso se realizaba como resultado de una amnistla $u$ otra forma de garantia. Se debia considerar que el Alto Comisionado tenla derecho a insistir en su interés legítimo en los resultados de cualquier operación de regreso que promoviera. Debería brindarle en el marco de consultas a fondo con el Estado interesado, acceso directo y sin obstáculos a las personas que regresaban, a fin de que estuviera en condiciones de vigilar el cumplimiento de las amnistias, las garantias y los compromisos que habian servido de base para el regreso de los refugiados. Deberla considerarse que ello era inherente a su mandato"14.

La DECLARACION DE CARTAGENA vino agregar al respecto un papel complementario otorgado al sistema interamericano de defensa y promoción de los derechos humanos de la Organización de los Estados Americanos (O.E.A.):

"DECIMO QUINTO. Promover el uso, con mayor intensidad, de los organismos competentes del sistema interamericano $y$, en especial, la Comisión Interamericana de Derechos Humanos con el propósito de complementar la protección internacional de los asilados y refugiados. Desde luego, para el cumplimiento de esas funciones el Coloquio considera que sería aconsejable acentuar la estrecha coordinación y cooperación existente entre la Comisión y el ACNUR". ${ }^{15}$

El Grupo de Expertos por CIREFCA confirmó el papel otorgado al ACNUR por la comunidad internacional, y sus derechos legítimos en la 
observancia del fiel cumplimiento de un programa de repatriación:

"61. El pais de asilo y el ACNUR como representante de la comunidad internacional poseen un interés reconocido en el desarrollo del retorno. En este sentido, tienen derecho a ser informados de los resultados de cualquier operación de repatriación voluntaria. Es por ello que la Oficina del Alto Comisionado debe dar seguimiento a la situación de los repatriados no solo durante la operación de repatriación sino también después de su retorno. Esta actividad es de caracter exclusivamente humanitario para constatar el cumplimiento de los acuerdos que sirvieron de base al retorno. No implicará privilegios o inmunidades para los repatriados y se ejerciera en el marco de consultas estrechas con el Estado en cuestión, que proporcionará al personal del Alto Comisionado acceso directo a los repatriados". ${ }^{16}$

Estos principios permitieron a CIREFCA reconocer que el esfuerzo en favor de los refugiados, repatriados y desplazados necesita tanto el apoyo, la cooperación y coordinación de los distintos gobiernos afectados o interesados, como de las distintas organizaciones intemacionales implicadas, en particular el ACNUR y el Programa de las Naciones Unidas para el Desarrollo (PNUD) ${ }^{17}$ También en su Plan de Acción Concertado, CIREFCA reiteró el compromiso de los programas de respetar el trabajo del ACNUR a favor de los repatriados, y su acceso a ellos. ${ }^{18}$

\section{PROGRAMAS DE ASISTENCIA}

Como se ha visto en la introducción el ACNUR tiene por función de preveer la protección internacional a los refugiados bajo su madato, asi como de buscar soluciones permanentes al problema de los refugiados, asistiendo en ese objetivo tanto los Gobiernos como las organizaciones privadas especializadas en tareas humanitarias. Asi lo prevee explicitamente el Estatuto del ACNUR en sus Artículos 1 y $8 .{ }^{19}$

EI Comité Ejecutivo del Programa del ACNUR precisó ese mandato "reconociendo que en determinadas situaciones podria ser preciso establecer arreglos apropiados con la Oficina para la recepción de los refugiados de retorno o para la preparación de proyectos con miras a su reintegración al pais de origen" 20 .

Con la adopción de la conclusión No. 40 (XXXVI), el Comité Ejecutivo instó a que la Cooperación Internacional se encaminará al logro de la repatriación voluntaria como solución y la desarrollará más a fondo. ${ }^{21}$

El Comité Ejecutivo agregó en dicha conclusión que la asistencia para la reintegración en el pais de origen por la comunidad intemacional favorecla la repatriación: 
"k) Las acciones internacionales para promover la repatriación voluntaria requerlan que se examinará la situación intema del pals de origen, asi como la del pais de acogida. Se reconoció que la asistencia para la reintegración de quienes regresaban, proporcionada por la comunidad internacional en el pais de origen, era un factor importante para promover la repatriación. A ese respecto, el ACNUR y otros organos competentes de las Naciones Unidas deblan de disponer de fondos fácilmente utilizables para ayudar a los refugiados que regresaban durante las diversas etapas de su integración y rehabilitación en su pais de origen;" 22

El mismo espíritu guió los esfuerzos para alentar las repatriaciones de los refugiados centroamericanos en forma paralela al proceso de pacificación en la región sobre los programas de asistencia por ejemplo, en el ACTA DE CONTADORA PARA LA PAZ Y COOPERACION EN CENTROAMERICA, el grupo de Contadora habia subrayado en varias conclusiones la necesidad de dirigirse a la solución del problema de los refugiados con programas de asistencia.

"65. Fortalecer los programas de protección y asistencia a los refugiados, sobre todo en los aspectos de salud, educación, trabajo y seguridad.

66. Que se establezcan programas y proyectos con miras a la autosuficiencia de los refugiados.

68. Solicitar a la comunidad internacional ayuda inmediata para los refugiados centroamericanos, tanto en forma directa, mediante convenios bilaterales o multilaterales, como a través del ACNUR y otros organismos y agencias." ${ }^{23}$

En particular, al respecto LA DECLARACION DE CARTAGENA concentró más tarde su atención sobre la situación de las personas desplazadas.

"NOVENA. Expresar su preocupación por la situación que padecen las personas desplazadas dentro de su propio pais. Al respecto, el Coloquio llama la atención de las autoridades nacionales y de los organismos internacionales competentes para que ofrezcan protección y asistencia a estas personas y contribuyan a aliviar la angustiosa situación en que muchos de ellos se encuentran." 24

Sobre la misma problemática, por su parte el Grupo de Expertos por CIREFCA recalcó que el éxito de una operación de repatriación dependia frecuentemente de los programas de asistencia. 
"63. El éxito de un programa de repatriación voluntaria depende frecuentemente de la adecuada asistencia que se suministre a los repatriados, por ello debe de incluir transporte y ayuda durante el viaje de retorno, asi como de las asistencia en el pais de origen durante el proceso de repatriación." 25

Incluso a la ocasión de los preparativos de CIREFCA, las Asambleas Generales de las Naciones Unidas y de la Organización de los Estados Americanos, como lo habian hecho en otras resoluciones en el pasado, llamaron la comunidad internacional a incrementar su asistencia a los palses de asilo y de origen de los refugiados Centroamericanos, a fín de fortalecer su capacidad de proporcionar los medios y servicios necesarios para la solución del problema de los refugiados, repatriados y personas desplazadas en concordancia con los programas nacionales de desarrollo. ${ }^{26}$

Estos llamados de la O.N.U. y de la O.E.A., tenian como objetivo dar un respaldo sólido al ACUERDO DE ESOUIPULAS II, PROCEDIMIENTO PARA ESTABLECER LA PAZ FIRME Y DURADERA EN CENTROAMERICA que establecia en su capitulo ocho la necesidad de encontrar solución al problema de los refugiados y desplazados en la región.

\section{REFUGIADOS Y DESPLAZADOS}

Los gobiernos Centroamericanos se Comprometen a atender con sentido de urgencia los flujos de refugiados y desplazados que la crisis regional ha provocado mediante protección y asistencia, especialmente en los aspectos de salud, educación, trabajo, y seguridad, asi como facilitar su repatriación, reasentamiento o reubicación, siempre y cuando sea de caracter voluntario y se manifieste individualmente.

También se comprometen a gestionar ante la comunidad internacional ayuda para los refugiados y desplazados Centroamericanos, tanto en forma directa, mediante convenios bilaterales o multilaterales, como por medio del Alto Comisionado de las Naciones Unidas para los refugiados (ACNUR) y otros organismos y agencias." 27

Es así que la obra principal de CIREFCA en 1989 consistió en reunir el conjunto de estos esfuerzos internacionales como nacionales alrededor de la globalidad del problema de los refugiados y personas desplazadas en la región Centroamericana, y de sus causas profundas. CIREFCA tuvo por misión de elaborar el marco de soluciones, asi como los mecanismos necesarios para implementarlas. 
CIREFCA, en este sentido, reiteró la necesidad del apoyo, de la cooperación y coordinación de todas las iniciativas y esfuerzos. La Conferencia confirmó igualmente EL COMPROMISO DE LA COMUNIDAD INTERNACIONAL en base a los PRINCIPIOS DE HUMANIDAD $Y$ SOLIDARIDAD a contribuir a la solución del problema en la región. ${ }^{20}$

\section{ROL DE LOS ORGANISMOS NO GUBERNAMENTALES}

Como se ha mencionado antes, el ACNUR asistió desde su creación a organizaciones privadas especializadas en tareas humanitarias para realizar varios programas de repatriación voluntaria en el mundo. EI ACNUR tiene mucha latitud en este sentido según su estatuto:

" 8. El Alto Comisionado deberá de asegurar la protección de los refugiados a quienes se extienda la competencia de la oficina del Alto Comisionado por los medios siguientes:

c) Asistiendo a los gobierno y a los particulares en su esfuerzo para fomentar la repatriación voluntaria de los refugiados o su asimilación en nuevas comunidades nacionales...

h) Estableciendo contacto, en la forma que juzgue más conveniente, con las organizaciones privadas que se ocupan de cuestiones de refugiados...

i) Facilitando la coordinación de los esfuerzos de las organizaciones privadas que se ocupan del bienestar social de los refugiados...

10. El Alto Comisionado administrará y repartirá entre los oganismos particulares $y$, eventualmente, entre los organismos públicos que considere más aptos para administrar tal asistencia los fondos, públicos o privados, que reciba con este fin."2o

Es decir que desde largo tiempo la comunidad internacional reconoce a- los distintos organismos no gubernamentales tanto intemacionales como nacionales un papel muy importante en el trabajo de búsqueda de soluciones y alivio a la tragedia de los refugiados. En muchas ocasiones las ONG's complementaron en forma muy adecuada el trabajo del ACNUR en su mandato de protección y asistencia a poblaciones de refugiados, entregando sus valiosas experiencias y conocimientos por su cercania a la realidad, tanto en tareas de apoyo a reintegración de los refugiados en sus propios medios 0 a su adaptación a nuevas comunidades nacionales.

Ese papel de las ONGs toma toda su importancia y su significación profunda cuando precisamente se trata de enfrentar las causas de los movimientos de refugiados, tarea a la cual el Comité Ejecutivo del 
Programa del ACNUR consagró mucha atención en su segunda Conclusión sobre repatriación voluntaria.

“c) La cuestión de las causas era fundamental para encontrar un solución, por lo que las iniciativas internacionales también deberán estar encaminadas a eliminar las causas de los movimientos de refugiados. Se debla de prestar mayor atención a las causas y a la prevención de esos movimientos, incluida la coordinación de las actividades que la comunidad intemacional y, en particular, las Naciones Unidas llevaban a cabo en la actualidad. Una condición fundamental para evitar las corrientes de refugiados era que los Estados directamente interesados tuvieran suficiente voluntad política de enfrentarse a las causas que provocaban los movimientos de refugiados";,

En el ACTA DE CONTADORA, el grupo de Contadora habia también, concluido en el mismo sentido que to hizo El Comité Ejecutivo del Programa del ACNUR cuando dijo:

"70. Que los gobiemos de área realicen los esfuerzos necesarios para erradicar las causas que provocan el problema de los refugiados". ${ }^{31}$

Muchos ONG's por su propio trabajo desde hace varios anos han justamente desarrollado actividades y recursos en este campo, donde gozan de gran credibilidad.

No hay que perder de vista que las poblaciones de refugiados son en la mayoría de los casos víctimas de actos de su propio Estado en su contra o de conflictos bélicos. Por ese motivo necesitan tiempo y comprensión para retomar una confianza a toda prueba hacia sus autoridades. A pesar de las garantías que éstas puedan ofrecerlos o el transcurso del tiempo en el exilio, muchos refugiados llegan a olvidar el pasado solo en forma muy lenta, y con muchas necesidades de asistencia.

De ese modo es sumamente útil el trabajo de organizaciones privadas y autónomas respecto al Estado de ayuda a los refugiados. Tales entidades, por la cercania y confianza que inspiran a los refugiados, pueden ayudar a crear condiciones propicias para una recuperación y reintegración sana, particularmente cuando las huellas del conflicto de origen estan todavía presentes en su contexto de retorno. Por esos motivos la comunidad internacional se apoya desde décadas en contribuciones privadas e independientes en la implementación de programas de repatriación. Estas contribuciones se han desarrollado en forma muy amplia en los últimos años.

LA DECLARACION DE CARTAGENA enfatizó justamente el rol de los organismos no gubernamentales en su aporte al alivio del problema 
de los refugiados en los términos siguientes:

"DECIMO CUARTA. Insta a las organizaciones no-gubernamentales internacionales y nacionales a que prosigan su encomiable labor coordinando su acción con el ACNUR, y con las autoridades nacionales del pals de asilo, de acuerdo con las directivas que éstas senalen." 32

Es tan asi que tanto la Asamblea General de las Naciones Unidas como la Asamblea General de la O.E.A., previamente a CIREFCA exhortaron también a todos los Estados miembros, a los órganos, organismos y agencias especializadas de su sistema respectivo, asI como.el conjunto de organizaciones regionales, subregionales, intergubernamentales y no gubernamentales vinculadas con la tarea humanitaria en favor de los refugiados Centroamericanos a colaborar entre ellas a la búsqueda de soluciones. ${ }^{33}$

El Grupo de Expertos por CIREFCA señaló muy a propósito que solo una asistencia adecuada y cercana a la realidad del contexto de los repatriados puede asegurar el éxito de un programa de repatriación:

"63 ...Esta última asistencia debe ser compatible con los Planes y proyectos de Desarrollo de la Comunidad a la cual retornan los refugiados. Dichos programas deberán de beneficiar a toda la comunidad incluyendo a los desplazados pudiendo mejorar también las condiciones generales de los lugares de retorno estimulando asl futuros movimientos de repatriación". ${ }^{34}$

En este contexto, con estos antecedentes, CIREFCA, vino a reconocer la contribución positiva de los organismos no-gubernamentales en el campo de la asistencia a favor de los grupos de la población afectada. ${ }^{35}$

Incluso dicha Conferencia alentó esas organizaciones a aumentar sus esfuerzos al interior del marco establecido por los gobiernos interesados (36). Finalmente CIREFCA dispuso la inclusión de la participación de las ONGs en el Plan de Acción Concertado. ${ }^{37}$

\section{HABRIA CONTRADICCION ENTRE LA VOLUNTARIEDAD INDI- VIDUAL DE LA REPATRIACION Y EL RETORNO DE REFU- GIADOS EN COMUNIDAD?}

Vale la pena reflexionar sobre la cuestión de saber si el retorno de refugiados en comunidad o en grupo es un fenómeno que contradice 0 se opone al principio de la voluntariedad individual de un programa de repatriación.

Una repatriación debe ser esencialmente voluntaria. Asi lo expresó el Comité del Programa del ACNUR como principio fundamental: 
"b) Subrayó que siempre debla respetarse el caractar esencialmente voluntario de la repatriación.

c) Reconoció la conveniencia de preveer arreglos apropiados para establecer el caracter voluntario de la repatriación, tanto en lo que se refiere a la repatriación individual como en el caso del movimiento de repatriación en gran escala, así como la conveniencia de que la Oficina de Alto Comisionado participase en dichos arreglos cuando fuese necesario". ${ }^{30}$

Tanto el ACTA DE CONTADORA como LA DECLARACION DE CARTADENA reiteraron ese principio:

"DUODECIMA. Reiterar el caracter voluntario e individual de la repatriación de los refugiados..." 39

En el mismo sentido se pronunció el Grupo de Expertos por CIREFCA

“59. El principio de la voluntariedad libremente expresada en forma individual es la piedra angular de la protección intemacional de los refugiados en el contexto de la repatriación voluntaria..." 40

CIREFCA en su Plan de Acción Concertado reiteró el compromiso en sus programas de "continuar respetando el caracter voluntario e individualmente manifestado de la repatriación" ${ }^{41}$

Es entonces unánime las opiniones sobre ese criterio. Pero qué significa en la práctica. Ese criterio significa la obligación del ACNUR de asegurarse de la plena voluntad y aceptación de un retorno y sus consecuencias por parte del refugiado, en forma individualizada. Este último debe expresarse en forma no equivoca, y escrita, que está de acuerdo por volver a su país. Solo asi se descargará la comunidad internacional de su deber de protección internacional, en el momento que se concretiza una repatriación como tal; es decir, en el momento que el refugiado pasa la frontera de su pais de origen y vuelve a ser sujeto de la protección de su país.

Ese modo que cumplir con su función de protección intemacional, no se contradice con un retorno en gran escala o en comunidad de refugiados. Cuando una colectividad de refugiados toma la decisión de volver a su patria, el deber de ACNUR es de asegurarse que los individuos que forman esa comunidad están bien de acuerdo a asumir una repatriación, y que cada uno de los miembros tomó una decisión libre, clara y personal al respecto. Después de concretizar su acto voluntario de manera individual, nada se opone a un retorno en gran escala ya sea masivo o en comunidad de un gnupo de personas refugiadas que ya vinieron de vivir varios años conjuntos, en el compartir 
ralces y realidades o que comparten origenes culturales y étnicas particulares.

\section{DOCUMENTOS DE IDENTIDAD}

Hasta la fecha, los repatriados masivos de diferentes asentamientos ubicados en los departamentos de Chalatenango, Cuscatlán, Cabahas, Usulutan y Morazán, tratan de reincorporarse al pais después de sus retomos masivos desde 1987, pero la gran mayoria, es decir alrededor de 29,000 según cifras mencionadas publicamente estan indocumentados.

El Comité Ejecutivo del ACNUR estudió el problema de la documentación y concluyó en 1980 que los Gobiemos interesados tenian que facilitar los trámites correspondientes:

i) Pidió a los Gobiernos interesados que facilitasen a los refugiados que fueran a repatriarse, los documentos de viaje, visados, permisos de entrada y medios de transporte necesarios y que, de haber perdido los refugiados su nacionalidad, hiciesen arreglos para que se les sustituyese de conformidad con la Legislación nacional;" "42

En 1985, el Comité Ejecutivo fue más explicitó todavia sobre las obligaciones de los Estados interesados cuando enunció que aquellos tenian que apoyar el ACNUR de modo cabal, y que las acciones para promover un programa de repatriación voluntaria no deblan crear obstáculos a un regreso espontáneo de los refugiados.

f) Todas las partes debian reconocer y respetar las preocupaciones humanitarias del Alto Comisionado y debian apoyarlo de modo cabal en sus iniciativas para cumplir su madato humanitario de proporcionar protección internacional a los refugiados y buscar una solución a los problemas de los refugiados;

h) Le reconoció la importancia del regreso espontáneo al pais de origen y se estimó que las acciones para promover la repatriación voluntaria organizada no debian crear obstáculos al regreso espontáneo de los refugiados. Los Estados interesados debian hacer todo lo posible, incluida la prestación de asistencia en el pais de origen, para estimular ese movimiento CUANDO SE CONSIDERARA OUE REDUNDARIA EN BENEFICIO DE LOS REFUGIADOS OUE SE TRATASE;" 43

Se puede concluir del conjunto de esos criterios del Comité Ejecutivo del Programa del ACNUR que es obligación del Estado de origen de entregar a los repatriados los documentos necesarios para volver a su pais, incluyendo de poner los recursos necesarios de asistencia para realizar los trámites sin demora. Además el Estado de origen no debe 
tratar de obstaculizar el retorno de refugiados por motivos de tales trámites o por otras razones.

EI Grupo de Expertos-por CIREFCA respaldó la necesidad por los repatriados de tener los mimos documentos que sus connacionales:

“62. Para facilitar el proceso de reintegración y también asegurar que los repatriados puedan efectivamente beneficiarse de la protección de las autoridades nacionales es importante que se le otorguen los mismos documentos de identidad que a sus compatriotas. Al fin de asegurar que obtengan el reconocimiento de su nacionalidad, debe regularizarse el registro de refugiados nacidos en el extranjero... Si las circunstancias lo permiten, el proceso de documentación, y registro deberá llevarse a cabo antes de realizarse la repatriación voluntaria". 4

CIREFCA confirmó está opinión en su Plan de Acción Concertado previendo programas cuyo objetivo será de facilitar la entrega de documentos:

"22. Los programas tienden, asimismo, a regularizar la situación de los repatriados en lo que se refiere al otorgamiento de documentes de identidad y el registro de nacimientos, matrimonios, fallecimientos u otros actos acaecidos en el país de asilo referidos al estado civil de las personas..." 45

\section{SUSPENSION O LIMITACION DEL DERECHO DE REPATRIACION}

Como hemos visto anteriormente los derechos de regresar libremente a su país, como los derechos de elección de su lugar de residencia y de libertad de movimiento son derechos precisos y categóricos. Además, como Derechos Humanos fundamentales son normas superiores del Derecho Internacional Público, limitativas del poder estatal, y cuyo respeto es del interés de toda la Comunidad de los Estados.

A pesar de ese carácter e importancia: esos tres derechos pueden ser suspendidos o limitados por los Estados. Sin embargo, es importante senalar que en tales casos de suspención o de limitación impuestas por un Estado, éste último debe de seguir varias condiciones muy estrictas de fondo y de forma para imponerlas antes de su implementación. Así lo preveen los instrumentos internacionales como veremos a continuación.

En forma general, podemos mencionar las limitaciones expresadas en la Declaración Universal de Derechos Humanos estipula en su artículo 29.1 que en el ejercicio de sus derechos y en el disfrute de sus libertades, toda persona estará solamente sujeta a las limitaciones establecidas por la ley con el único fin de lograr el reconocimiento y el respeto de los derechos y las libertades de los demás, y de satisfacer las 
justas exigencias de la moral, del orden público y del bienestar general en una sociedad demócratica. Entonces una primera condición prevista por la Declaración es que las limitaciones deben ser fijadas por leyes, y no por simples declaraciones políticas de funcionarios.

\section{Derecho de regresar llbremente a su pais}

La garantía del derecho fundamental de regresar libremente a su pals no puede ser objeto de limitación ó restricción sino únicamente suspendida. Así lo prevee el Pacto Internacional de Derechos Civiles y Pollticos en su Artículo 4.1:

Art.4.1 En situaciones excepcionales que pongan en peligro la vida de las Naciones y cuya existencia haya sido proclamada oficialmente, los Estados partes en el presente Pacto podrán adoptar disposiciones que, en la medida estrictamente limitada a las exigencias de la situación zpendan las obligaciones contraidas en este pacto, siempre que tales disposiciones no sean imcompatibles con las demás obligaciones que les impone el Derecho Internacional y no extranen discriminación alguna fundada únicamente en motivos de raza, color, sexo, idioma, religión y origen social.

El Artículo 4.3 del mismo Pacto prevee el mecanismo de ejercicio de la suspensión de las garantías establecidas.

Art.4.3.- Todo Estado parte en el presente Pacto que haga uso del derecho de suspensión deberá de informar inmediatamente a los demás Estados en el presente Pacto, por conducto del Secretarla General de las Naciones Unidas, de las disposiciones cuya aplicación haya suspendido y de los motivos que hayan suscitado la suspensión. Se hará una nueva comunicación por el mismo conducto en la fecha que haya dado por terminada tal suspensión.

Por su lado, la Convención Americana sobre Derechos Humanos prevee en su Artículo 27 la posibilidad de suspensión de Garantlas.

Art. 27.- Suspensión de Garantías

1. En caso de guerra, de peligro público o de otra emergencia que amenace la independencia o seguridad del Estado parte, este podrá adoptar disposiciones que, en la medida y por el tiempo estrictamente limitados a las exigencias de la situación, suspendan las obligaciones contraidas en virtud de esta convención siempre que tales disposiciones no sean incompatibles con las demás obligaciones que les impone el Derecho Internacional y no entranen discriminación alguna fundada en motivos de raza, color, sexo, idioma, religión u origen social. 
También, la Convención prevee en el Artículo 27.3 que el Estado que hace uso del derecho de suspensión debera informar inmediatamente a los demás estado partes de la Convención, por conducto del Secretario General de la O.E.A., de las disposiciones de cuya aplicación ha suspendido, de los motivos que suscitaron la suspensión asi como de la fecha que se terminara dicha suspensión.

Por último vale recordar que la Constitución de la República prevee en su Artículo 29 un régimen de excepción (llamado también estado de sitio) que permite de suspender la garantía de no prohibición de la entrada en el territorio a los Salvadorenos.

El régimen de excepción, se aplicará en casos de guerra, invasión del terrotorio, rebelión, sedición, catástrofe, epidemia u otra calamidad general o de graves perturbaciones del orden público.

Es importante de notar que según la Constitución, tal suspensión podría afectar la totalidad o parte del territorio de la República y también que dicha suspensión tiene que ser aprobada por medio del Decreto del Organo Legislativo o del Organo Ejecutivo. Además es importante de notar que tal suspensión no puede ser proclamada por más de 30 dias a la vez, y solo si la situación de emergencia que la justifica persiste.

Hay que senalar que el Estado de El Salvador no ha suspendido legalmente esas garantias desde Enero de 1987, y ha indicado en reiteradas ocasiones que tal suspensión no era necesaria, salvo al momento de la ofensiva del FMLN cuando fueron suspendidas dichas garantias del 16 de noviembre de 1989 hasta marzo de 1990. Eso significa que fuera del tiempo de aplicación del estado de sitio, no existia en el país ninguna suspensión del derecho de regresar libremente a su país, y en consecuencia ninguna justificación legal a los impedimientos impuestos al retorno espontaneo de los miles de refugiados que to hicieron desde 1987.

Derechos de libre elecclón del lugar de residencla y libertad de movimlento.

Vale comentar de entrada que estos dos derechos pueden ser suspendidos en la misma forma y bajo las mismas condiciones que el derecho de regresar libremente a su pais, tal como lo hemos expuesto en los párrafos precedentes.

Además de ser suspendidos, estos derechos pueden sufrir limitaciones y restricciones por parte del Estado, siempre que éste respete unas condiciones de fondo y de forma, como veremos a continuación. 
El Pacto Internacional de Derechos Civiles y Políticos prevee que estos derechos no podrán ser objetivo de restricciones salvo cuando éstas se hallan previstas en la ley, sean necesarias para proteger la seguridad nacional, el orden público, la salud o la moral pública o los derechos y libertades de terceros, y sean compatibles con los demás derechos reconocidos en el Presente Pacto.

En cuanto a la Convención Americana sobre Derechos Humanos el Articulo 22.3 prevee al respecto:

“ 22.3.- El ejercicio de los derechos anteriores no puede ser restringido sino en virtud de una ley, en la medida indispensable en una sociedad democrática, para prevenir infracciones penales o para proteger la seguridad nacional, la seguridad o el orden público, la moral o la salud pública o los derechos y libertades de los demás.

Tomando en cuenta que estos instrumentos tienen obligatoriedad en El Salvador, eso trae como consecuencia que cualquiera limitación o restricción impuesta por el Estado salvadoreho a estos dos derechos debe proceder por vía de una legislación especlfica al respecto al interior del cuadro estricto determinado por dichos instrumentos. Es obvio entonces que ninguna limitación o restricción puede imponerse por puras declaraciones políticas y públicas por parte de autoridades salvadorenas civiles o militares.

En otras palabras, el Estado de El Salvador podrá limitar o restringir los derechos de libertad de elección de su lugar de residencia o de circulación en el país de sus ciudadanos repatriados solo si adopta una ley, un decreto o una reglamentación al respecto y muy especifica a la zona - lugar de retorno que se trate. En caso contrario, no podría limitar o restringir estos derechos básicos o fundamentales.

\section{CONCLUSIONES}

Ese trabajo fue elaborado en las visperas de los retornos masivos de refugiados salvadorenos que se ubicaban en Honduras, principalmente en los campamentos de Mesa Grande, San Antonio y Colomoncagua en 1989. Ya varios refugiados del campamento de Mesa Grande hablan retornado desde 1987. Así algunos temas ilustrados en el presente trabajo no presentaban más dificultades, pero otros si tenlan su plena vigencia, en particular mencionamos los problemas de la documentación. de las garantias y condiciones de seguridad y dignidad asi como el trato discriminatorio, la libertad de tránsito, que aún en la actualidad tienen plena vigencia, ya que han sido derechos constantemente violados, especialmente por las autoridades militares. 
En cuanto a los retornos masivos de 1989 , todos los temas tenian su importancia. Hoy dia, los refugiados que volvieron en 1989 y 1990 se encuentran en las mismas situaciones que sus correligionados que los precedieron en el retorno con las mismas dificultades y mismos problemas sin solución, en particular los problemas de la documentación, de la ausencia de garantias y la falta de respeto a su derecho de libre tránsito (PROCESO No.446, "El problema de la documentacion de los repatriados y desplazados" )

$Y$ todavia este trabajo tiene vigencia porque el proble,ma de los refugiados tadavia no ha terminado. Se encuentran hoy dia varios miles de refugiados en el campamento de Mesa Grande, y que manifestado sus deseos de volver a su Patria. Por otro lado, en el caso de los refugiados de Panama se presentaron en el camino de dichos compatriotas todos los obstáculos de un verdadero calvario para ellos; incomprension institucional y uso propagandistico y para fines políticos, ideológicas y partidistas de su situación de indigencia, de desposesion y vulnerabilidad por parte del Gobierno de la Republica asi como de algunos voceros del partido gobemante ARENA.

En particular, hubo disputa sobre el lugar eligido por la comunidad para reestablecerse. También el estudio del caso revela múltiples esfuerzos por parte del gobierno de la República para impedir el retorno " en comunidad " de los refugiados hasta llegar a intentos de " parcelar la comunidad " misma.(PROCESO No.458, "Dificil repatriacion de los refugiados de Ciudad Romero"). En ese caso, los comentarios hechos sobre los criterios aplicables en el presente artículo cobran su plena vigencia y vuelven a ser muy actuales.

En definitiva el Estado salvadoreño esta firmemente ligado a múltiples normas y compromisos internacionales en esta materia. Algunos son leyes en el pais, otras normas sin tener ese caracter obligatorio tienen de toda forma un valor interpretativo muy importante como fuentes secundarias de derecho. En definitiva, no tiene el Estado Salvadoreno otra posibilidad que de conformarse con los preceptos del Derecho Internacional en la materia y respetar su propia Ley fundamental.

Por eso justamente cuando se firmó el Acuerdo sobre Derechos Humanos, en San José, Costa Rica, el 26 de julio de 1990 entre el Gobiemo y el FMLN en el cuadro de la negociacion, se incluyó compromiso sobre estas materias en el Acuerdo. Este último hecho constituye incluso un reconocimiento que el Estado no estaba cumpliendo en esta materia conforme al derecho intemo a sus obligaciones internacionales.

En el campo del derecho internacional de los derechos humanos, desde la aprobación de la Carta de las Naciones Unidas, no es falso de 
considerar que "los derechos humanos de los ciudadanos de cada Estado dejaron de ser asunto de jurisdicción interna, y por primera vez en la historia de la humanidad, los Estados asumieron una obligación legal internacional de respetar los derechos humanos de los hombres y mujeres que viven dentro de sus fronteras. A partir también de ese momento, las Naciones Unidas pudieron exigir a sus Estados Miembros que rindieran cuentas ante ese máximo organismo intemacional, por la violación de los derechos humanos, no siendo válido juridicamente alegar que con tal actitud se lesiona la soberanía de los Estado, por cuanto ellos admitieron, al suscribir este tratado multilateral, efectuar cierta concesión de soberanía, en esta materia".40

Tal como lo hizo entrever la crisis en el Golfo Pérsico, y la situación de Irak frente a las resoluciones del Consejo de Seguridad de las Naciones Unidas, el Estado salvadoreno no escapa a esta nueva realidad contemporanea.

\section{CITAS}

1. ESTATUTO DE LA OFICINA DEL ALTO COMISIONADO DE LAS NACIONES UNIDAS PARA LOS REFUGIADOS, Anexo de la Resolución 428 (v) de la Asamblea General del 14 de Diciembre de 1950. En recopilación de instrumentos internacionales relativos al asilo y a los refugiados publicado por ACNUR - División de Protección Internacional, Ginebra, 1984, P. 23.

2. RES. A.G. ONU 32/71; 31/35; 32/77; 32/26; 34/60; 35/41; 36/125; 37/195; 38/121; 39/140; 40/118; 41/124; 42/109;

3. DECLARACION DE CARTAGENA, Coloquio sobre la Protección Internacional de los Refugiados en América Central, México y Panamá: Problemas Jurldicos y Humanitarios. Copatrocinado por la Universidad de Cartagena de Indias, Facultad de Derecho, el Centro Regional de Estudios del Tercer Mundo y el Alto Comisionado de las Naciones Unidas para los Refugiados bajo los auspicios del gobierno de la República de Colombia (Cartagena, 19 - 22 de noviembre de 1984) en publicación del ACNUR, Ginebra, 1985. Parte III, P. 16.

4. PRINCIPIOS Y CRITERIOS PARA LA PROTECCION Y ASISTENCIA A LOS REFUGIADOS, repratiados y desplazados centoamericanos on América latina. Documento elaborado a la ocasión de la confrencia Internacional sobre refugiados Centroamericanos (CIREFCA) por el grupo de expertos integrado por el Doctor Hector Gros Espiell,Vice-presidente de la Corte Interamericana de Derechos Humanos; la Doctora Sonia Picado, Juez de la Corte Interamericana de Derechos Humanos y Directora Ejecutiva del Instituto Interamericano de Derechos Humanos; y el Doctor Leo Valladares Lanza, miembro de la Comisión Interamericana de Derechos Humanos. CIREFCA /89/9. Abril 1989. p. 12 
5. Proyecto de Declaración y Plan de Acción concertado en favor de los Refugiados, Repatriados y Desplazados Centroamericanos. Conferencia Internacional sobre Refugiados Centroamericanos (CIREFCA). Ciudad de Guatemala, 29 al 31 de Mayo de 1989. CIREFCA /89/13/ REV. I. MAYO 1989, II, Parte Uno, D, 1, par. 21 d) p. 12.

6. Conclusión Aprobada por el Comité Ejecutivo del Programa del Alto Comisionado por Recomendación del Sub-Comité Plenario sobre Protección Internacional, 1980. (310. perlodo de sesiones del Comité Ejecutivo) publicado en Conclusiones sobre la Protección Internacional de los Refugiados, Aprobadas por el Comité Ejecutivo del Programa del ACNUR. Publicación de la Olicina del Atto Comisionado de las Naciones Unidas para los Refugiados, Ginebra, 1981. P. 41.

7. Conclusión Aprobada por el Comité Ejecutivo del Programa del Alto Comisionado por Recomendación del Sub-comité Plenario sobre Protección Internacional. 1985 (360. perlodo de sesiones del Comité Ejecutivo) IBID., p. 90-91.

8. Op. cit. 3, Parte III, p. 16

9. Op. cit. 4, p. 13

10. Op. cit. 5,1 , par. 3, p. 4

11. Op. cit. 5, II, Primera parte, C, par. 14, p.10

12. Op. cit. 5, II, Primera parte, D, 1, par. 21 c), p.12

13. Op. cit. $6, p .41$

14. Op. cit. 7, p. 93

15. Op. cit. 3, Parte III, p. 16

16. Op. cit. 4, p. 14

17. Op. cit. $5, I$, par. 18 y $21, p .5$ y 6

18. Op. cit. 5, II, Primera parte, D, 1, par. 21 h), p.12

19. Op. cit. 1, p. 23 y 24

20. Op. cit. 6, p. 41

21. Op. cit. 7, p. 91

22. Op. cit. 7, p. 93

23. ACTA DE CONTADORA PARA LA PAZ Y COOPERACION EN CENTROAMERICA. Parte I, Capitulo IV, Sección 2, par. 65, 66 y 68

24. Op. cit. 3, Parte III, p. 16

25. Op. cit. 4, p. 14

26. RES. A.G. ONU AC.3/43/L.60; RES A.G. OEA AG/DOC 2370/88 REV. 1

27. ACUERDO DE ESQUIPULAS II - Procedimiento para establecer la paz firme y duradera en Centroamérica, Capítulo 8.

28. Op. cit. 5, I, par. 13, p. 5

29. Op. cit. 1, p. 24

30. Op. cit. 7, p. 91

31. Op. cit. 23, Parte I, Capítulo IV, Sección 2, par. 69

32. Op. cit. 3, Parte III, p. 16

33. Op. cit. 26

34. Op. cit. 4, p. 14

35. Op. cit. 5, I, par. 17, p. 5 
36. IBID

37. Op. cit. 5, II, Segunda parte, B, par. 36, p. 15

38. Op. cit. 6, p. 40

39. Op. cit. 3, Parte III, p. 16

40. Op. cit. 4, p. 13

41. Op. cit. 5, II, Primera parte, C, par. 21 a), p. 12

42. Op. cit. 6, p. 41

43. Op. cit. 7, p. 92

44. Op. cit. 4, p. 14

45. Op. cit. 5, II, Primera parte, C, par. 22, p. 12

46. Fólix Lavina, Sistemas internacionales de protección de los derechos humanos, Buenos Aires: Ediciones De Palma, 1987, p.16.

\section{APENDICE}

A continuación se presentan los principales apuntes jurídicos de los proyectos de repatriación de los refugiados salvadoreños.

- En la práctica de la comunidad internacional la REPATRIACION VOLUNTARIA a su pals de origen o su propia comunidad es la solución más adecuada al problema de los refugiados.

- Existe amplio reconocimiento del derecho de repatriación basado en el derecho de regresar libremente a su pais, norma establecida en numerosos instrumentos jurídicos tanto a nivel internacional, regional como interno de El Salvador.

- La REPATRIACION VOLUNTARIA puede ejercerse al lugar de origen o de anterior residencia de los refugiados o en otro lugar libremente escogido por los refugiados en virtud de esos otros derechos de libertad de elección de sus lugares de residencia y libertad de movimiento, normas también establecidas en numerosos instrumentos jurldicos tanto al nivel internacional, regional como interno de El Salvador.

- Los derechos de regresar libremente a su pais, de libertad de elección de su lugar de residencia como de libertad de movimiento son normas imperativas del Derecho Internacional Público como normas fundamentales de los Derechos Humanos. Pertenecen al ser humano por su condición de persona y limitan asl lo poderes de los Estados.

- El respeto de tales normas, como valores superiores, constituye una obligacion fundamental para los Estados. Además es innegable que todos los Estados tienen interés en su observancia, a título de miembros de la Comunidad de los Estados. La violación de una norma de tal importancia resulta ser una infracción grave que tiene como consecuencia poner en 
juego la responsabilidad internacional del estado infractor frente a los demás Estados.

- Un programa de REPATRIACION VOLUNTARIA debe desarrollarse con garantlas, bajo un contexto de seguridad personal y de dignidad según los criterios y la práctica internacional en la materia.

- Ese contexto de seguridad y de dignidad se deriva del Derecho Internacional Público, del Derecho Internacional de los Derechos Humanos, de los criterios y principios de la Protección internacional de los refugiados asi como de las normas del Derecho Internacional Humanitario.

- Es innegable hoy en día que la Comunidad Internacional y el Alto Comisionado de las Naciones Unidas para los Refugiados (ACNUR) como su representante, tienen un interés fundamental en los programas de REPATRIACION VOLUNTARIA y a su fiel cumplimiento conforme al Derecho Internacional Público y a la garantlas ofrecidas por el pals de origeri.

- En la búsqueda de soluciones al problema de los refugiados, el ACNUR, desde su creación, está asistiendo a los Gobiernos como a las organizaciones privadas (las ONG's) especializadas en tareas humanitarias de repatriación voluntaria. Incluso este modo de hacer es previsto por su propio Estatuto.

- En la misma búsqueda de soluciones al problema de los refugiados es obligación del Estado de origen de adoptar todas las medidas requeridas para ayudar a la realización de una operación de repatriación.

- Además es obligación de los Estados encarar el problema básico de las causas que provocaban los movimientos de refugiados. Asi las iniciativas internacionales deben ser encaminadas a eliminar estas causas.

- Incluso es una condición fundamental para evitar las corrientes de refugiados que los Estados derectamente interesados tuvieran suficiente voluntad política de enfrentarse a las causas que provocan los movimientos.

- Tanto la Asamblea General de las Naciones Unidas como el organo correspondiente de la Organización de los Estados Americanos reconocen el rol de los organismos no gubernamentales en el esfuerzo global de solución al problema de loṣ refugiados centroamericanos.

- Asi mismo la Conferencia Internacional sobre Refugiados Centroamericanos (CIREFCA) reconoció la contribución de los organismos no-gubernamentales en el campo de la asistencia a favor de los grupos de la población afectada.

- Un PROGRAMA DE REPATRIACION basado en el respeto de la voluntariedad individual del refugiado no se contradiga ni se oponga al retorno en gran escala, masivo o en comunidad de un grupo de refugiados que comparten raices y realidades, siempre y cuando la intención es clara y no equivoca por parte de cada miembro de dicho grupo de refugiados. 
- Es obligación del Estado de origen de entregar a los repatriados los mismos documentos de identidad que a sus compatriotas, asi como los documentos necesarios para volver a su pais. Es también obligación del Estado de origen de poner los recursos necesarios para realizar los trámites sin demora, al mismo tiempo que debe abstenerse de obstaculizar el retorno de refugiados por motivos de tales trámites.

- Los derechos de regresar libremente a su país de origen, de libre elección de su lugar de residencia y de libertad de movimiento pueden ser suspendidos, a pesar de su importancia como derechos básicos y fundamentales, por parte de los Estados. En tales casos, dichos Estados deben seguir varias condiciones muy estrictas de fondo y forma según los instrumentos juridicos internacionales en la materia, justamente por sus valores intrinsecas.

- En particular, hay que subrayar que el Estado de El Salvador no puede suspender dichos derechos sin seguir éstas condiciones estrictas de fondo y forma. Además, en tal caso, el Estado salvadoreño está obligado a adoptar previamente un Decreto específico por parte del Organo Legislativo o del Organo Ejecutivo, proclamando el régimen de excepción, según la Constitución de la República.

- Los derechos de libre elección de su lugar de residencia y de libertad de movimiento pueden ser igualmente limitados siempre cuando los Estados siguen las condiciones de fondo y forma previstos por los instrumentos juridicos internacionales aplicables a la materia, en particular deben adoptar una ley especifica sobre la limitación de que se trata. 